\title{
Comparative Effect of Propofol and Thiopentone Sodium in Sheep Sedated with Xylazine Hydrochloride
}

\author{
Rahim Dad Brohi ${ }^{1, *}$, Amir Bukhsh Kalhoro', Allah Bux Kachiwal', Illahi Bux Kalhoro', \\ Dildar Hussain Kalhoro', Sarfaraz Ahmed ${ }^{2}$, Farhan Anwar Khan ${ }^{3}$, Hira Sajjad Talpur', \\ Zia-ur-Rehman ${ }^{1}$ and Dinesh Bhattaria ${ }^{4}$ \\ ${ }^{1}$ Faculty of Animal Husbandry and Veterinary Sciences, Sindh Agriculture University, \\ Tandojam, Pakistan
}

${ }^{2}$ National Center of Meat Quality and Safety Control, College of Food Science and Engineering, Nanjing Agricultural University, Nanjing, China

${ }^{3}$ Department of Animal Health, Faculty of Animal Husbandry \& Veterinary Sciences, The University of Agriculture, Peshawar

${ }^{4}$ Department of Veterinary Gynecology and Obstetrics, Institute of Agriculture and Animal Science, Tribhuvan University, Nepal

\begin{abstract}
A B S T R A C T
Combination effect of propofol $(6 \mathrm{mg} / \mathrm{kg})$ and thiopentone sodium $(8 \mathrm{mg} / \mathrm{kg})$ administrated intravenously after premedication with xylazine hydrochloride $(0.02 \mathrm{mg} / \mathrm{kg})$ has been studied on six healthy female sheep using a crossover design. During xylazine therapy the pulse rate was significantly $(\mathrm{P}<0.01)$ decreased, but respiratory rate remained unchanged. The administration of anesthesia on the other hand caused a significant $(\mathrm{P}<0.01)$ increase in the pulse rate and a significant $(\mathrm{P}<0.01)$ decrease in the respiratory rate. The body temperature decreased $(\mathrm{P}<0.01)$ with all the three anesthetic regimens. The means of safe induction of anesthesia (propofol, $14.00 \pm 0.2582$; and thiopentone sodium, $14.83 \pm 0.1667$ seconds) and duration of anesthesia (thiopentone sodium, $14.50 \pm 0.2236$ and propofol, $13.22 \pm 0.1014 \mathrm{~min}$ ), and a full recovery from anaesthesia (thiopentone sodium, $13.67 \pm 0.4216$; and propofol, $12.45 \pm 0.2432 \mathrm{~min}$ ) were differed from one another. Comparing the results of this study, it is concluded that the intravenous therapy of propofol caused a smooth quality of induction and recovery from anesthesia. Based on the measured parameters it also concludes that propofol is preferably recommended as safe therapy than thiopentone sodium for the surgical operations. Moreover, anesthetic regimens can safely be used in sheep in field as well as hospital conditions.
\end{abstract}

Article Information
Received 14 October 2016
Revised 12 January 2017
Accepted 18 March 2017
Available online 14 November 2018
Authors' Contribution
RDB and ABK conceived and
designed the experiments, performed
experiments, interpreted the data
and wrote the article. All other
authors helped in preparation of the
manuscript.
Key words
Xylazine, Propofol, Thiopentone
sodium, Sedation, General
anaesthesia.

\section{INTRODUCTION}

$\mathrm{X}$ ylazine is a thiazine derivative and acts as an agonist at the $\alpha 2$ class of adrenergic receptors (Bonfanti et al., 2016). Xylazine hydrochloride is clinically used for sedative, analgesic and muscle relaxant properties during minor surgical and diagnostic procedures (Clarke and Hall, 1990). Xylazine is highly lipophilic nature and directly stimulates the central $\alpha 2$ adrenergic receptors and leads to a decrease in neurotransmission of norepinephrine and dopamine in the central nervous system (Shi et al., 2016). In veterinary anesthesia, it is a very common procedure of combination therapy and xylazine is often used in combination with ketamine because xylazine reduces the required dose of anaesthetic. In sheep and goat, its

\footnotetext{
* Corresponding author: kkrahim_jan@yahoo.com 0030-9923/2019/0001-0001 \$9.00/0

Copyright 2019 Zoological Society of Pakistan
}

dose ranges from 0.02 to $0.2 \mathrm{mg} / \mathrm{kg}$ (Pöppel et al., 2015). Urination following administration of xylazine is very common in sheep and goats due to lower levels of vasopressin hormone (Ghurashi, 2016). Xylazine significantly reduce the heart rate in animals and also cause hypersalivation in cattle, sheep, and goat, which is diminished by pre-treating with atropine (Giroux et al., 2015; Thanusu et al., 2010).

Propofol slows the activity of brain and nervous system and used as an injectable general anaesthetic surgery in veterinary and human medicine for the induction and maintenance of anaesthesia (Lou et al., 2015). It is a rapidly acting intravenous anaesthetic, producing anaesthesia for a short duration with rapid and smooth onset and recovery (Thompson and Godalle, 2000). A single bolus dose provides approximately $10 \mathrm{~min}$ of anaesthesia, with complete recovery occurring within 20 to $30 \mathrm{~min}$ in dogs and cats (Maney et al., 2013). Propofol at the dose rate of $5-7 \mathrm{mg} / \mathrm{kg}$ i.v. is sufficient to induce anaesthesia 
in sheep and goats (Kumar et al., 2014). Propofol has a fatal potential to depress respiration and to decrease blood, intramuscular and intraocular pressures. The principal site for the metabolism of propofol is the liver, whiles kidneys contribute to the extrahepatic clearance of propofol (Zonca et al., 2012).

Thiopentone sodium is one of the most widely drug in the induction of general anesthesia (Krauss and Green, 2000) and it is an ultra-short acting barbiturate, immediately after intravenous injection, thiopental rapidly reaches the CNS, and its effects become apparent within 15-30 sec and duration of anaesthesia is 10-20 min (Andaluz et al., 2012; Goldstein and Aronow, 1960). The full recovery from anesthesia occurs within 1 to $2 \mathrm{~h}$ (Bush et al. 1966). The principal site for the metabolism is the liver and the metabolites excreted in urine (Srishti et al., 2012). The dose range to induce anaesthesia in the animals is about 7 to $20 \mathrm{mg} / \mathrm{kg}$ (Davis and Cladis, 2005; Winters et al., 1955).

Typically, the minor surgical procedures in sheep can be performed with physical restraint and under local sedation. Nevertheless, the major surgical problems and emergencies like dystokia, fractures, tumors, hernia, testicular abnormalities etc. may require sedation and general anaesthesia. Drugs, such as xylazine, propofol and thiopental sodium are commonly used for sedation and short duration of general anaesthesia in ruminants, including sheep. A very limited research has been done on effects of propofol and thiopentone sodium after intravenous administration. In this study evaluation of effects of propofol and thiopentone sodium in sheep sedated with xylazine hydrochloride has been investigated for the cardiorespiratory responses, including body temperature, means of induction of anesthesia, duration of anesthesia, and a full recovery from anesthesia was measured.

\section{MATERIALS AND METHODS}

\section{Animals}

Six healthy adult sheep (female) with an average age of $22.67 \pm 2.6$ months (mean $\pm \mathrm{SE}$ ) weighing 25.83 $\pm 2.2 \mathrm{~kg}$ (mean $\pm \mathrm{SE}$ ) were used in this study. Sheep were kept at Livestock Experimental Station, Faculty of Animal Husbandry and Veterinary Sciences. The animals were allowed to adapt to the surroundings for at least two weeks before experiment. All the sheep were given thorough physical examination and dewormed with Nilzan plus ${ }^{\circledR}$ (ICI). Sheep were vaccinated against enterotoxaemia and contagious pleuropneumonia (Veterinary Research Institute).

\section{Dosage regimen and experimental design}

All sheep were ear tagged with number from 1 to 6. They were fed alpha and barseem. All drugs were administered intravenously. Xylazine (Sedaziner ${ }^{\circledR}$; Fort Dodge Animal Health, USA) at the dose rate of $0.02 \mathrm{mg} /$ $\mathrm{kg}$ body weight was used for premedication 5 min before

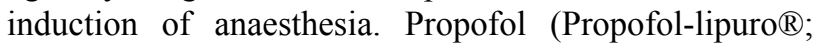
B. Braun Melsungen AG, Melsungen Germany) and thiopentone sodium (Pentothal $\AA$; Abbot,) at the dose rate of $8 \mathrm{mg} / \mathrm{kg}$ and $12 \mathrm{mg} / \mathrm{kg}$, of body weight respectively were administered for induction of anaesthesia. The experimental design and assessment of anaesthetic and clinical indices were done in sheep with multimodal therapy of xylazine/propofol (treatment A) and xylazine/ thiopentone sodium (treatment $\mathrm{B}$ ) using a crossover design with at least two weeks interval between each treatments.

\section{Experimental procedure}

Before start of each experiment sheep were weighed and brought to surgery-hall for the experiment. Animals were off fed for $12 \mathrm{~h}$ before start of experiment. Water was available adlibitum. Wool over the left and right jugular vein was clipped with an electric hair clipper and the skin sites were disinfected with an antiseptic (tincture iodine). The sedative and anaesthetics were administered using a disposable syringe in the right jugular vein. Xylazine was injected slowly. Anaesthesia was induced with propofol and thiopental sodium given as a bolus dose (Okwudili et al., 2014).

For anaesthetic indices the degree, duration, onset of sedation and anaesthesia; nature and duration of recovery; standing time; and duration of recumbency in each animal were recorded with each treatment.

The degree of sedation was graded according to Kalhoro et al. (2010), and 0, No sedation (animal is alert); 1, Light degree of sedation (slight effect with animal becoming quieter with its head lowered below shoulder but above knee); 2, Moderate degree of sedation (animal becoming less alert, partial closure of eyelids with its head lowered below knee); 3, Deep degree of sedation (animal becoming ataxic and recumbent). The degree of anaesthesia was graded according to Verstegen et al. (1991).

\section{Statistical analysis}

The data was analysed using one way analysis of variance (ANOVA) and Tukey-Kramer Multiple Comparison test with the Graph Pad Prism 5.0 (Instant, Graph Pad Software, San Degio, USA).

\section{RESULTS}

\section{Pulse rate}

As shown in Figure 1A, the pulse rate of all animals significantly $(\mathrm{P}<0.01)$ decreased after administration of xylazine. After $5 \mathrm{~min}$ of induction of anaesthesia pulse 
rate increased significantly $(\mathrm{P}<0.01)$ from control and preinduction values in all groups of treatments. The treatment A produced a maximum increase in pulse rate at $15 \mathrm{~min}$, on the other hand treatment $\mathrm{B}$ peaked the pulse rate in 5 min only. The increased pulse rate showed a decreased trend in the pulse rate and reached the control values after 40 and 30 min with treatments $\mathrm{A}$ and $\mathrm{B}$, respectively.
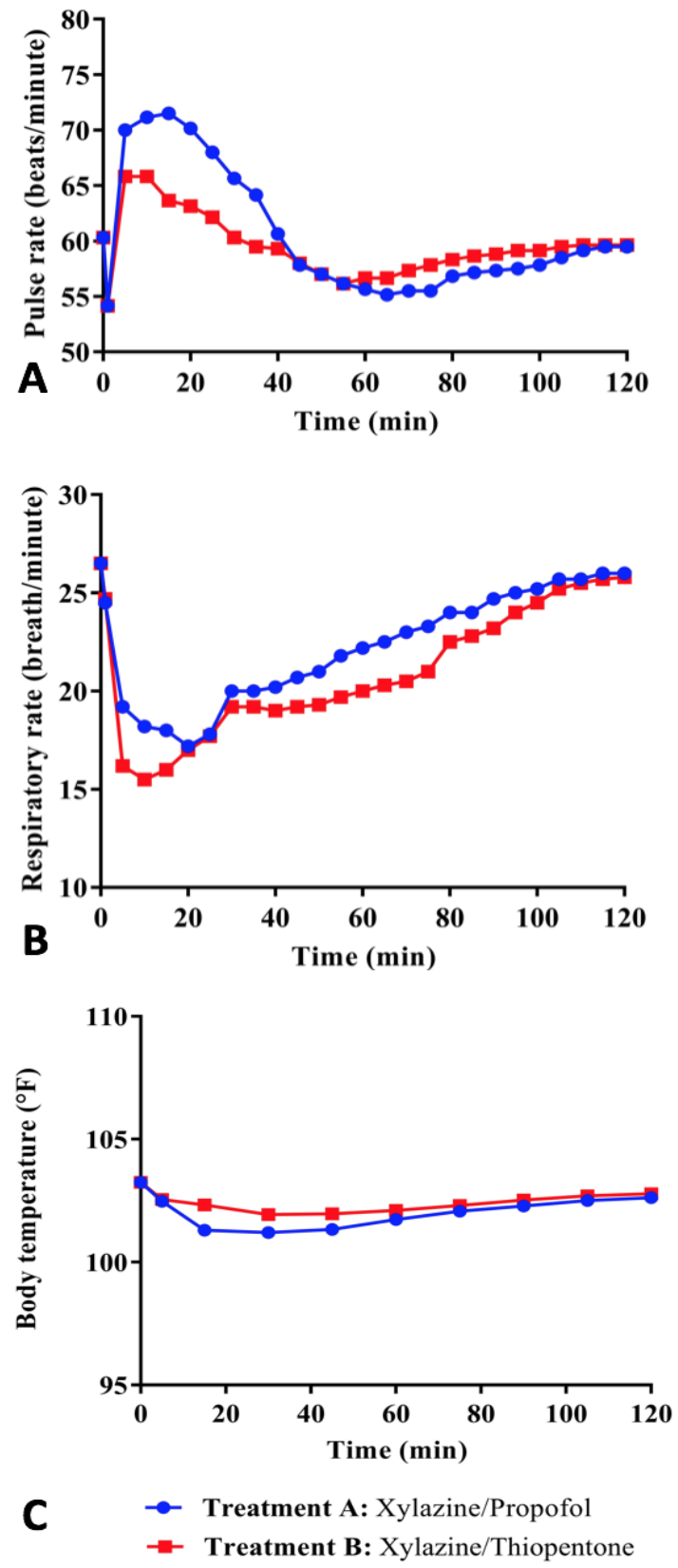

Fig. 1. Changes in mean pulse rate (beats/min) (A), respiratory rate (beats $/ \mathrm{min})(\mathrm{B})$ and body temperature $\left({ }^{\circ} \mathrm{F}\right)$ (C) following intravenous administration of xylazine / propofol and xylazine / thiopentone.

\section{Respiratory rate}

After 5 min of induction of anaesthesia, respiratory rate was significantly $(\mathrm{P}<0.01)$ decreased from control values up to $75 \mathrm{~min}$ and $90 \mathrm{~min}$ in treatments $\mathrm{A}$ and B, respectively (Fig. 1B). A maximum down-fall was occurred at $20 \mathrm{~min}$ in treatment $\mathrm{A}$, and $10 \mathrm{~min}$ in treatments $\mathrm{B}$ and $\mathrm{C}$. Later on, it was started to increase and reached the baseline values at $90 \mathrm{~min}$ in treatment $\mathrm{A}$ and at $95 \mathrm{~min}$ treatments B (Fig. 1B).

\section{Body temperature}

Induction of anaesthesia with propofol and thiopentone significantly decreased $(\mathrm{P}<0.01)$ the body temperature as compared to control value and maximum decrease occurred at $30 \mathrm{~min}$ with both treatments. The body temperature continued to decrease further next $20 \mathrm{~min}, 15$ min and 10 min with treatment $\mathrm{A}$ and $\mathrm{B}$, respectively (Fig. 1C).

\section{Onset and degree of sedation}

Xylazine produces signs of sedation within 56.67 \pm 2.789 and $56.67 \pm 2.472$ seconds in treatments $A$ and B, respectively (Fig. 2A). No recumbency was observed in all animal groups. Xylazine produced Light degree of sedation $(+)$ in all groups.

\section{Induction of anaesthesia}

Induction of anaesthesia after administration of anaesthetic agents was $14.00 \pm 0.2582$ and $14.83 \pm 0.1667$ seconds in treatments A and B, respectively (Fig. 2B). The induction of anaesthesia was rapid $(\mathrm{P}<0.01)$ with propofol and thiopentone. Induction of anaesthesia with propofol and thiopentone sodium was significantly increased $(\mathrm{P}<0.01)$ the pulse rate from control and pre-induction values in all animals. Comparison of treatments showed that propofol caused more changes in pulse rate than thiopentone sodium. Induction of anaesthesia with propofol caused decrease in respiratory rate which remained significantly lowered $(\mathrm{P}<0.01)$ from control values up to $75 \mathrm{~min}$, in thiopentone sodium up to $90 \mathrm{~min}$. The induction of anaesthesia with propofol and thiopentone sodium significantly decreased $(\mathrm{P}<0.01)$ the body temperature as compared to control values.

\section{Duration and degree of anaesthesia}

The mean duration of anaesthesia after administration of propofol and thiopentone was $13.22 \pm 0.1014$ and $14.50 \pm 0.2236 \mathrm{~min}$, respectively (Fig. 2C). There were significantly difference $(\mathrm{P}<0.01)$ between treatment $\mathrm{A}$ and $\mathrm{B}$, respectively. Surgical anaesthesia (stage III- plane I) was produced in all animals with all the anaesthetic regimens. 


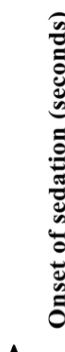

$\mathbf{A}$
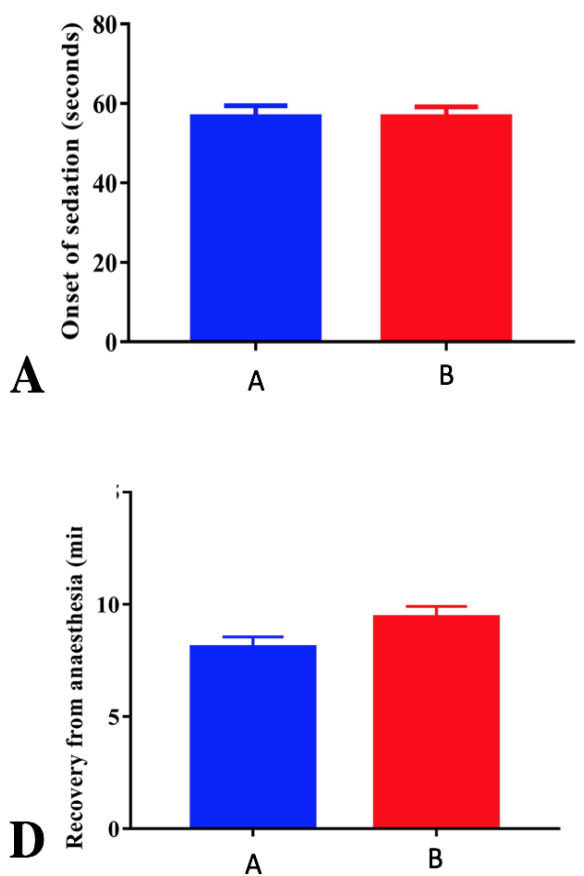
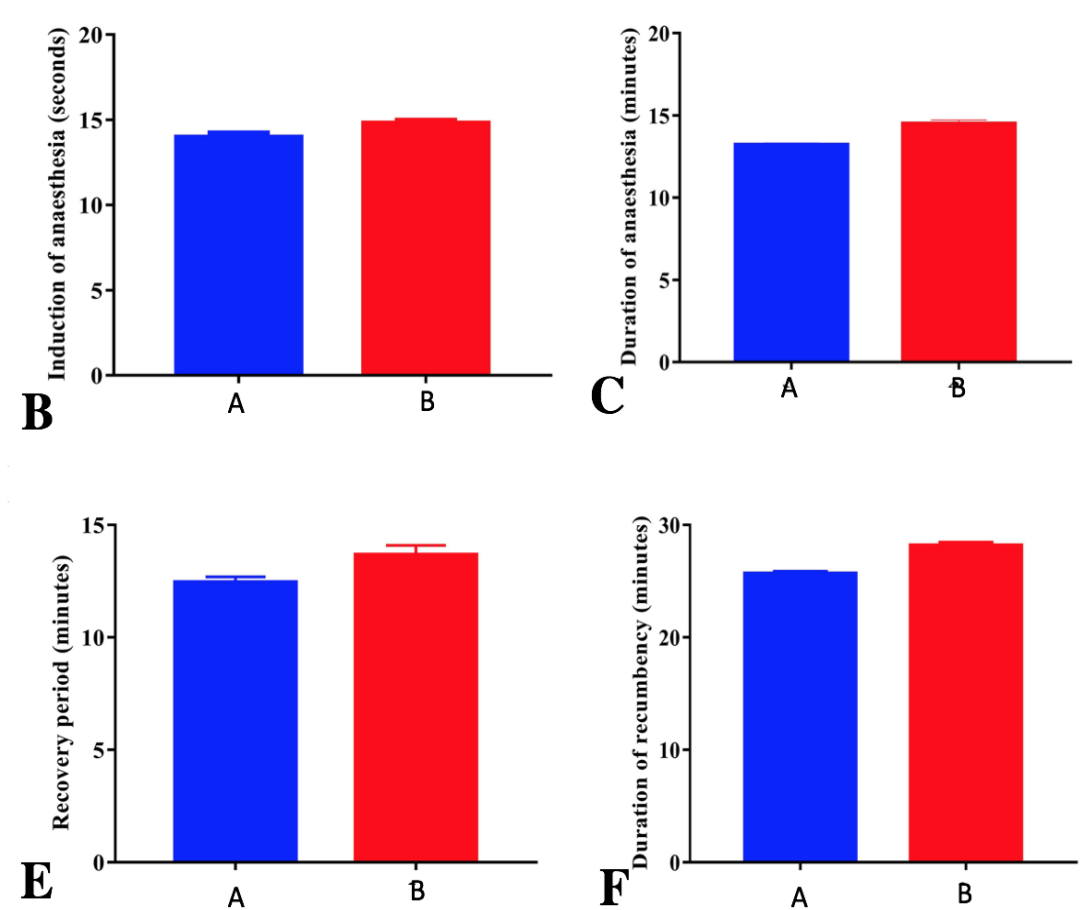

Fig. 2. The assessment of multiple anesthetic indices following intravenous administration of xylazine/propofol (treatment $A$ ) and xylazine/thiopentone (treatment B). A, Onset of sedation; B, Induction of anaesthesia; C, Duration of anaesthesia; D, Recovery time from anaesthesia; E, Recovery period; F, Duration of recumbency.

\section{Recovery from anaesthesia}

Recovery from anaestheisa was safe and excitement free with all three treatments. No any complication such as cardiac arrest, respiratory arrest, profound respiratory depression, excitement, myostitis and nerve paralysis occurred during anaesthesia and recovery period. Frequent urination, staggering, wobbling, and defecation were observed in all animals with all treatments during recovery. Recovery was smooth and all animals stood after $8.09 \pm 0.4589$ and $9.43 \pm 0.4814$ min with propofol and thiopentone, respectively (Fig. 2D).

\section{Recovery period}

The mean recovery time with treatment A and B were $12.45 \pm 0.2432$ and $13.67 \pm 0.4216 \mathrm{~min}$, respectively (Fig. 2E). Duration of recovery from anaesthesia in treatment was significantly shorter $(P<0.01)$ than treatment $A$ and $B$.

\section{Duration of recumbency}

Xylazine pre-medication not produced recumbency in all animals in all treatments. After induction of anaesthesia all the animals were recumbent. The mean duration of recumbency with treatment $\mathrm{A}$ and $\mathrm{B}$ was $25.67 \pm 0.2108$ and $28.17 \pm 0.3073 \mathrm{~min}$, respectively (Fig. 2F). There were significantly difference $(\mathrm{P}<0.01)$ between treatment $\mathrm{A}$ and B.

\section{Other observations}

Together with above mentioned anaesthetic indices with the multimodal therapy of drugs, several other effects were observed such as wobbling, head drooping, and no recumbency were observed in all animals with xylazine administration. Apnoea was predominantly more prolonged after induction of propofol anaesthesia than with other two treatments. The palpebral reflex, pedal reflex, swallowing reflex, jaw tone, movement of limbs and tail were absent in all animals after administration of all three anaesthetic regimens, while nystagmus, corneal reflex, snoring, arrhythmias, anal relaxation, muscle relaxation, protrusion of tongue, jugular pulsation, frequent urination, tympany were observed in all animals with all treatments. Moreover, the muscle relaxation with treatments A is more pronounced than treatment $\mathrm{B}$.

\section{DISCUSSION}

Rapid and smooth induction of anesthesia is desirable in ruminants in field as well as hospital conditions. The present study was carried out to study and compare 
efficacy of bolus doses of two rapidly acting intravenous anesthetics (propofol: $6 \mathrm{mg} / \mathrm{kg}$ and thiopentone sodium: 8 $\mathrm{mg} / \mathrm{kg}$ ) preceded by intravenous administration of xylazine $(0.02 \mathrm{mg} / \mathrm{kg})$ as pre-medication in six sheep under same experimental conditions.

Onset of sedation was within 56.67 seconds which is similar to Moolchand et al. (2014), who reported onset of sedation in goats within 20 seconds after intravenous administration of xylazine $(0.02 \mathrm{mg} / \mathrm{kg}$ body weight $)$ (Moolchand et al., 2014), and the rapid onset of sedation after apha ${ }_{2}$-agonist administration reported by other workers in sheep (Runciman et al., 1990) and in goats (Okwudili et al., 2014).

Administration of xylazine significantly decresased $(\mathrm{P}<0.01)$ the pulse, respiratory rates and body temaperature. Significant decrease in pulse and not respiratory rates after pre-anaesthetic administration of alpha ${ }_{2}$-agoinst have been reported by other researchers in sheep (Mather et al., 2004) and in goats (Shi et al., 2016). Significant changes in the body temperature after xylazine administration in sheep have also been reported by others in sheep and in goats (Okwudili et al., 2014). However, significant decrease in rectal temperature has been reported in buffalo calves (Runciman et al., 1990).

After induction of anesthesia with propofol, pulse rate significantly increased $(\mathrm{P}<0.01)$ and respiratory rate siginificantly decreased $(\mathrm{P}<0.01)$. Similar results were reported by other workers in sheep (Runciman et al., 1990; Lin et al., 1994), in goats (Celestine et al., 2014; Prassinos et al., 2005) and in calves (Sebel et al., 2006). Decrease in the pulse rate after initial transient increase has been reported in goat (Celestine et al., 2014). Decrease in respiratory rate after propofol anesthesia has also been reported by other researchers in sheep (Lin et al., 1994), and in goats (Celestine et al., 2014; Prassinos et al., 2005). This study shows that thiopentone has more respiratory depressant effect $(20.00+0.45)$ as compared to propofol anesthesia $(22.17+0.60)$. Similar effects have also been reported by Redondo et al. (2000) in dogs.

Decrease in body temperature with propofol and thiopentone anesthesia has also been reported by other researchers in sheep (Runciman et al., 1990) and in goats (Prassinos et al., 2005). Longer duration of anesthesia with Thiopentone sodium than propofol has been reported by Moolchand et al. (2014) in goats. Quicker recovery with propofol anesthesia has also been reported sheep (Laitinen, 1990) in goats (Prassinos et al., 2005).

\section{CONCLUSION}

Based on the results from this study, xylazine $(0.02$ $\mathrm{mg} / \mathrm{kg}$ ) pre-treatment produced satisfactory sedation in sheep and induced the duration of anaesthesia for conducting minor surgical procedures without any serious side effect like cardiac arrest or respiratory arrest. Intravenous administration of propofol and thiopentone sodium as bolus doses produced rapid, safe and excitement free induction of anaesthesia. All anaesthetic regimes produced sufficient duration of anaesthesia for conducting minor short duration surgical procedures without any serious side effects. Considering the parameters measured, propofol is graded superior than thiopentone sodium because of smoother and fast induction of anesthesia and a long length recovery from anaesthesia.

\section{Statement of conflict of Interest}

The authors have no conflict of interest to declare.

\section{REFERENCES}

Andaluz, A., Felez-Ocana, N., Santos, L., Fresno, L. and Garcia, F., 2012. The effects on cardio-respiratory and acid-base variables of the anaesthetic alfaxalone in a 2-hydroxypropyl- $\beta$-cyclodextrin (HPCD) formulation in sheep. Vet. J., 191: 389-392. https:// doi.org/10.1016/j.tvj1.2011.03.017

Bonfanti, E., Cosnier, F., Wathier, L. and Campo, P., 2016. Measurement of ketamine and xylazine in rat brain by liquid-liquid extraction and gas chromatography-mass spectrometry. J. pharmacol. toxicol. Methods, 77: 6-9. https://doi.org/10.1016/j. vascn.2015.09.001

Bush, M. T., Berry, G. and Hume, A., 1966. Ultra-shortacting barbiturates as oral hypnotic agents in man. Clin. Pharmacol. Therap., 7: 373-378. https://doi. org/10.1002/cpt196673373

Celestine, A.D.N., Beiermann, B.A., May, P.A., Moore, J.S., Sottos, N.R. and White, S.R., 2014. Fractureinduced activation in mechanophore-linked, rubber toughened PMMA. Polymer, 55: 4164-4171. https://doi.org/10.1016/j.polymer.2014.06.019

Clarke, K. and Hall, L., 1990. A survey of anaesthesia in small animal practice: AVA/BSAVA report. Vet. Anaesth. Analg., 17: 4-10. https://doi. org/10.1111/j.1467-2995.1990.tb00380.x

Davis, P.J. and Cladis, F.P., 2005. The use of ultrashort-acting opioids in paediatric anaesthesia. Clin. Pharmacok., 44: 787-796. https://doi. org/10.2165/00003088-200544080-00002

Ghurashi, M.A.H., 2016. Assessment and comparison of three selected total intravenous anaesthetic infusion combinations in donkeys. Sudan University of Science and Technology.

Giroux, M.C., Hélie, P., Burns, P. and VaCHon, P., 2015. 
Anesthetic and pathological changes following high doses of ketamine and xylazine in Sprague Dawley rats. Exp. Anim., 64: 253. https://doi.org/10.1538/ expanim.14-0088

Goldstein, A. and Aronow, L., 1960. The durations of action of thiopental and pentobarbital. $J$. Pharmacol. Exp. Therap., 128: 1-6.

Kalhoro, A., Tariq, M., Kachiwal, A., Rind, R., Kalhoro, D. and Kalhoro, S., 2010. Use of medetomidine hydrochloride as sedative in cattle calves. Pak. J. Agric. Agril. Engg. Vet. Sci., 26: 87-99.

Krauss, B. and Green, S.M., 2000. Sedation and analgesia for procedures in children. New Engl. J. Med., 342: 938-945. https://doi.org/10.1056/ NEJM200003303421306

Kumar, R., Kinjavdekar, P., Aithal, A., Pawde, A., Kumar, A., Singh, J., Khattri, S. and Madhu, D., 2014. Clinicophysiological, haematobiochemical and haemodynamic effect of propofol and ketamine with dexmedetomidine in urolithic goats. Vet. World, 7: 566-573. https://doi.org/10.14202/ vetworld.2014.566-573

Laitinen, O., 1990. Clinical observations on medetomidine/ketamine anaesthesia in sheep and its reversal by atipamezole. Vet. Anaesth. Analg., 17: 17-19. https://doi.org/10.1111/j.1467-2995.1990. tb00382.x

Lin, H.C., Wallace, S.S., Tyler, J.W., Robbins, R.L., Thurmon, J.C. and Wolfe, D.F., 1994. Comparison of tiletamine-zolazepam-ketamine and tiletaminezolazepam-ketamine-xylazine anaesthesia in sheep. Aust. Vet. J., 71: 239-242.

Lou, P.H., Lucchinetti, E., Zhang, L., Affolter, A., Gandhi, M., Zhakupova, A., Hersberger, M., Hornemann, T., Clanachan, A.S. and Zaugg, M., 2015. Propofol (Diprivan $\AA$ ) and Intralipid $\AA$ exacerbate insulin resistance in type-2 diabetic hearts by impairing GLUT4 trafficking. Anesth. Analg., 120: 329-340. https://doi.org/10.1213/ ANE.0000000000000558

Maney, J.K., Shepard, M.K., Braun, C., Cremer, J. and Hofmeister, E.H., 2013. A comparison of cardiopulmonary and anesthetic effects of an induction dose of alfaxalone or propofol in dogs. Vet. Anaesth. Analg.,, 40: 237-244. https://doi. org/10.1111/vaa.12006

Mather, L.E., Duke, C.C., Ladd, L.A., Copeland, S.E., Gallagher, G. and Chang, D.H., 2004. Direct cardiac effects of coronary site-directed thiopental and its enantiomers: A comparison to propofol in conscious sheep. J. Am. Soc. Anesthesiol., 101: 354-364. https://doi.org/10.1097/00000542-

\section{0-00016}

Moolchand, M., Kachiwal, A., Soomro, S. and Bhutto, Z., 2014. Comparison of sedative and analgesic effects of xylazine, detomidine, and medetomidine in sheep. Egypt. J. Sheep Goat Sci., 9: 43-48.

Okwudili, U.C., Athanasius, E.C. and Ijeoma, U.R., 2014. Assessment of common anaesthetic and clinical indices of multimodal therapy of propofol, xylazine, and ketamine in total intravenous anaesthesia in West African dwarf goat. J. Vet. Med., 2014: Article ID 962560. http://dx.doi. org/10.1155/2014/962560

Pöppel, N., Hopster, K., Geburek, F. and Kästner, S., 2015. Influence of ketamine or xylazine supplementation on isoflurane anaesthetized horses - a controlled clinical trial. Vet. Anaesth. Analg., 42: 30-38. https://doi.org/10.1111/vaa.12176

Prassinos, N.N., Galatos, A.D. and Raptopoulos, D., 2005. A comparison of propofol, thiopental or ketamine as induction agents in goats. Vet. Anaesth. Analg., 32: 289-296. https://doi.org/10.1111/j.14672995.2005.00204.x

Redondo, J.I., Gomez-Villamandos, R.J., Dominguez, J.M. and Santisteban, J.M., 2000. Propofol or thiopentone as induction agents in romifidinesedated and halothane-N2O-anesthetized dogs: a preliminary study. Canadian J. Vet. Res., 64: 249.

Runciman, W., Mather, L. and Selby, D., 1990. Cardiovascular effects of propofol and of thiopentone anaesthesia in the sheep. Br. J. Anaesth., 65: 353-359. https://doi.org/10.1093/bja/65.3.353

Sebel, L.E., Richardson, J.E., Singh, S.P., Bell, S.V. and Jenkins, A., 2006. Additive effects of sevoflurane and propofol on $\gamma$-aminobutyric acid receptor function. J. Am. Soc. Anesthesiol., 104: 1176-1183. https://doi.org/10.1097/00000542-20060600000012

Shi, X.X., Yin, B.S., Yang, P., Chen, H., Li, X., Su, L.X., Fan, H.G. and Wang, H.B., 2016. Xylazine activates adenosine monophosphate-activated protein kinase pathway in the central nervous system of rats. PLoS One, 11: e0153169. https://doi.org/10.1371/journal. pone. 0153169

Srishti, K., Srishti, K., Lalita, M. and Ashish, B., 2012. A study of pharmacokinetics of histological examination. Res. J. Pharmaceut., 1: 1-6.

Thanusu, J., Kanagarajan, V. and Gopalakrishnan, M., 2010. Synthesis, spectral characterization, and in vitro antibacterial and antifungal activities of novel 1, 3-thiazine-2-amines comprising morpholine nucleus. J. Enzyme Inhib. med. Chem., 25: 756764. https://doi.org/10.3109/14756360903389898 
Thompson, K.A. and Goodale, D.B., 2000. The recent development of propofol (DIPRIVAN®). Intens. Care Med., 26: S400-S404. https://doi.org/10.1007/ PL00003783

Verstegen, J., Fargetton, X., Donnay, I. and Ectors, F., 1991. An evaluation of medetomidine/ketamine and other drug combinations for anaesthesia in cats. Vet. Rec., 128: 32-35. https://doi.org/10.1136/ vr.128.2.32

Winters, W., Spector, E., Wallach, D. and Shideman, F., 1955. Metabolism of thiopental-S35 and thiopental-
2-C14 by a rat liver mince and identification of pentobarbital as a major metabolite. J. Pharmacol. Exp. Therap., 114: 343.

Zonca, A., Ravasio, G., Gallo, M., Montesissa, C., Carli, S., Villa, R. and Cagnardi, P., 2012. Pharmacokinetics of ketamine and propofol combination administered as ketofol via continuous infusion in cats. J. Vet. Pharmacol. Therap., 35: $580-587$. https://doi.org/10.1111/j.13652885.2012.01377.x 